\title{
Impact of Polymer Microstructure on the Self-Assembly of Amphiphilic Polymers in Aqueous Solutions
}

\author{
Roger C. W. Liu, Agnès Pallier, Marc Brestaz, Nadège Pantoustier, Christophe Tribet*
}

Laboratoire de Physico-Chimie des Polymères et des Milieux Dispersés, CNRS UMR 7615, ESPCI, 10 rue Vauquelin, F-75005 Paris, France

christophe.tribet@espci.fr 


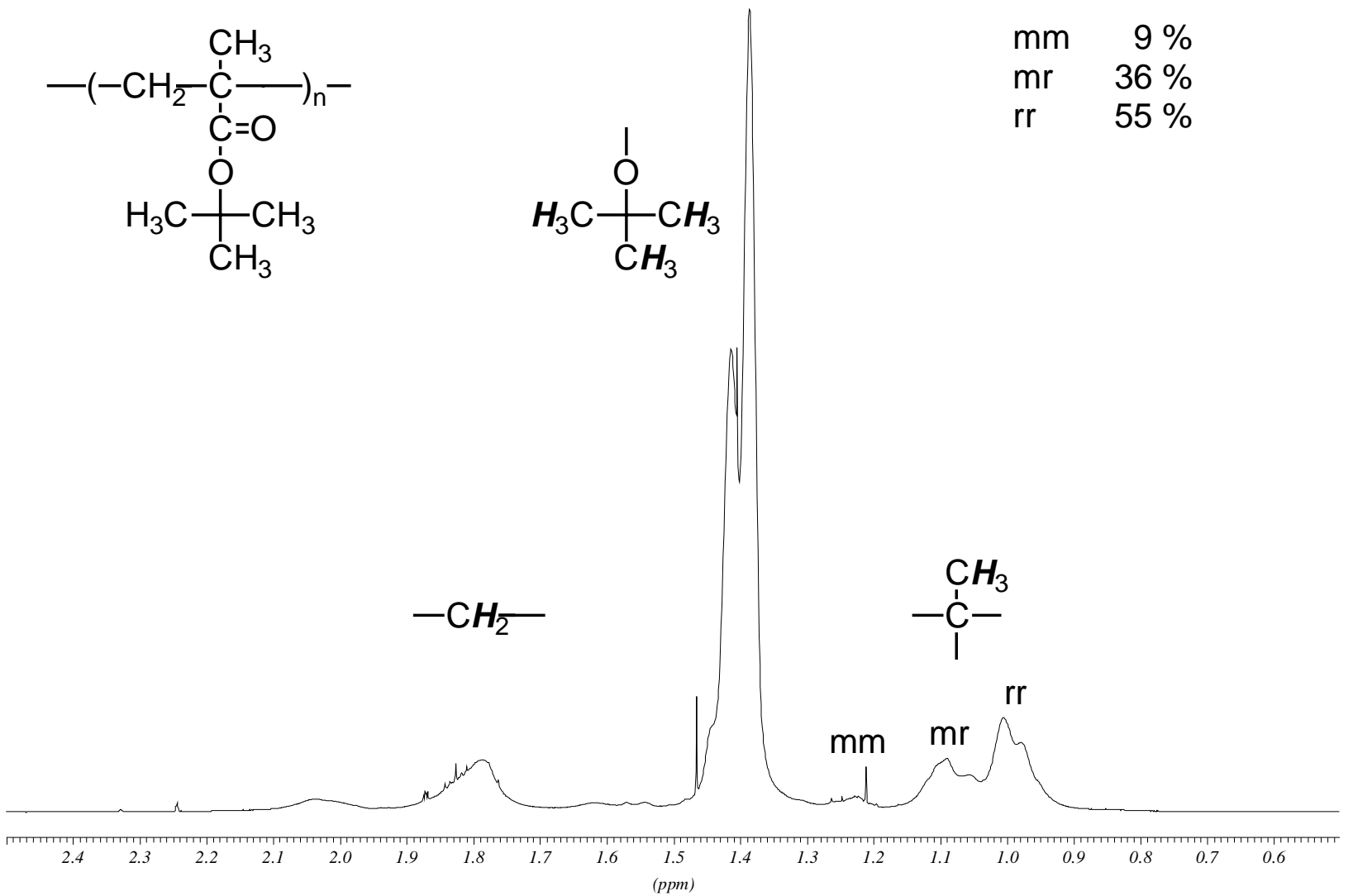

Supplemental Figure 1. ${ }^{1} \mathrm{H}$ NMR spectrum of poly(tert-butyl methacrylate) in $\mathrm{CDCl}_{3}$. 


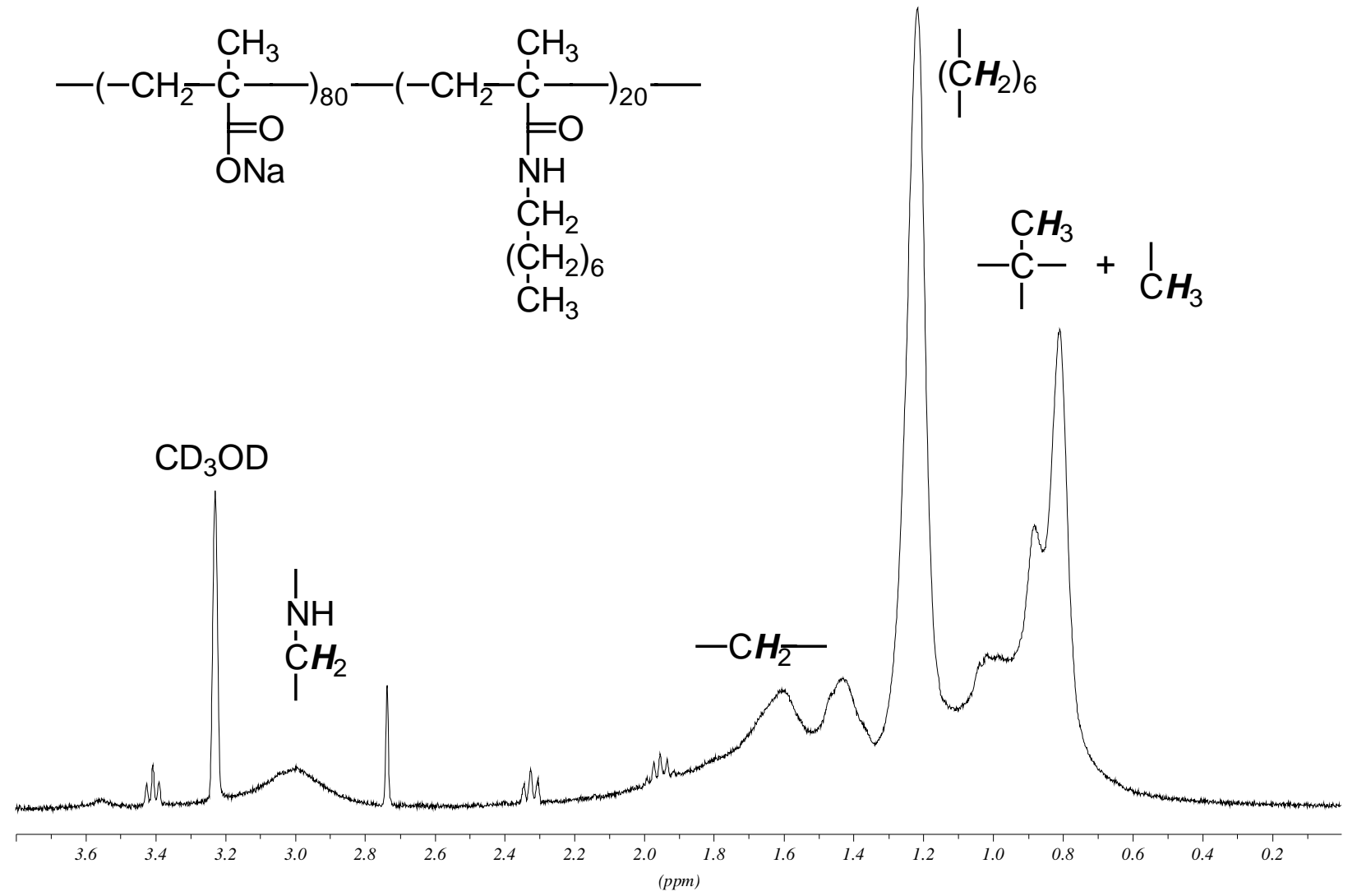

Supplemental Figure 2. ${ }^{1} \mathrm{H}$ NMR spectrum of AP107-20R in $\mathrm{CD}_{3} \mathrm{OD} / \mathrm{D}_{2} \mathrm{O}(20 / 80 \mathrm{v} / \mathrm{v})$. 